This item was submitted to Loughborough's Research Repository by the author.

Items in Figshare are protected by copyright, with all rights reserved, unless otherwise indicated.

\title{
Investigation on the removal of the major cocaine metabolite (benzoylecgonine) in water matrices by UV254/H2O2 process by using a flow microcapillary film array photoreactor as an efficient experimental tool
}

\section{PLEASE CITE THE PUBLISHED VERSION}

http://dx.doi.org/10.1016/j.watres.2015.11.059

\section{PUBLISHER}

Elsevier / IWA Publishing (@ 2015 Elsevier Ltd.)

\section{VERSION}

AM (Accepted Manuscript)

\section{PUBLISHER STATEMENT}

This work is made available according to the conditions of the Creative Commons Attribution-NonCommercialNoDerivatives 4.0 International (CC BY-NC-ND 4.0) licence. Full details of this licence are available at: https://creativecommons.org/licenses/by-nc-nd/4.0/

\section{LICENCE}

CC BY-NC-ND 4.0

\section{REPOSITORY RECORD}

Puma, Gianluca Li, Danilo Russo, Danilo Spasiano, Marianna Vaccaro, Kristin H. Cochran, Susan D.

Richardson, Roberto Andreozzi, Nuno M. Reis, and Raffaele Marotta. 2016. "Investigation on the Removal of the Major Cocaine Metabolite (benzoylecgonine) in Water Matrices by UV254/H2O2 Process by Using a Flow Microcapillary Film Array Photoreactor as an Efficient Experimental Tool". figshare.

https://hdl.handle.net/2134/20002. 
1 Investigation on the removal of the major cocaine metabolite (benzoylecgonine) in

2 water matrices by $\mathrm{UV}_{254} / \mathrm{H}_{2} \mathrm{O}_{2}$ process by using a flow microcapillary film array

3 photoreactor as an efficient experimental tool.

5 Danilo Russo $^{\mathrm{a} \dagger}$, Danilo Spasiano ${ }^{\mathrm{a}}$, Marianna Vaccaro ${ }^{\mathrm{a}}$, Kristin H. Cochran ${ }^{\mathrm{b}}$, Susan D. Richardson ${ }^{\mathrm{b}}$,

6 Roberto Andreozzi ${ }^{\mathrm{a}}$, Gianluca Li Puma ${ }^{\mathrm{c}}$, Nuno M. Reis ${ }^{\mathrm{c}}$, Raffaele Marotta ${ }^{\mathrm{a}}$

${ }^{a}$ Dipartimento di Ingegneria Chimica, dei Materiali e della Produzione Industriale, Università di

9 Napoli “Federico II”, p.le V. Tecchio, 80 - 80125 - Napoli, Italy.

$10{ }^{\mathrm{b}}$ Department of Chemistry and Biochemistry, University of South Carolina, Columbia, SC 29208, 11 USA.

$12{ }^{\mathrm{c}}$ Environmental Nanocatalysis \& Photoreaction Engineering Department of Chemical Engineering, 13 Loughborough University, Loughborough LE11 3TU, UK.

\section{Abstract}

16 A microcapillary film reactor (MCF) was adopted to evaluate and compare the removal efficiency

17 of benzoylecgonine (BE), an emerging micropollutant deriving from illicit drug abuse (cocaine), in different aqueous matrices: milliQ water, synthetic and real wastewater and surface water. The removal processes investigated were the direct photolysis with UV radiation at $254 \mathrm{~nm}$, and the advanced oxidative process (AOP) with the same UV radiation and hydrogen peroxide. As a result of the microfluidics approach developed through an innovative experimental apparatus, full conversion of $\mathrm{BE}$ was reached within a few seconds or minutes of residence time in the MCF depending on the process conditions adopted. The radiation dose was estimated to be approximately

$245.5 \mathrm{~J} \mathrm{~cm}^{-2}$. The innovative MCF reactor was found to be an effective tool for photochemical studies, 25 especially when using highly priced, uncommon, or regulated substances. The removal efficiency 
was affected by the nature of the aqueous matrix, due to the presence of different xenobiotics and natural compounds that act primarily as $\mathrm{HO}^{\circ}$ radical scavengers and secondly as inner $\mathrm{UV}_{254}$ filters. Moreover, nano-liquid chromatography (LC)-high resolution-mass spectrometry analysis was utilized to identify the main reaction transformation products, showing the formation of hydroxylated aromatics during the photochemical treatment.

(1)

(1)

${ }^{\dagger}$ Corresponding author. Tel.: +39 081 7682253; fax: +39 081 5936936. E-mail address:

danilo.russo3@unina.it (D. Russo).

$\$$ Corresponding author. Tel.: +44 (0)1509 222510; fax: +44 (0)1509 223923. E-mail address:

$$
\text { G.Lipuma@lboro.ac.uk (G. Li Puma). }
$$

Keywords: microcapillary film photoreactor; advanced oxidation processes; benzoylecgonine; wastewater; surface waters; emerging micropollutants

\section{Introduction}

\subsection{Benzoylecgonine as an emerging pollutant}

In the last few decades, non-conventional micropollutant removal is an emerging research focus

(Asu et al., 2011; Corominas et al., 2013). The improvement in analytical technologies and the

increasing consumption of both illicit and legal drugs by the world population allowed the

discovery and identification in wastewater effluents (WW) and surface water (SurW) of new classes

of contaminants, such as pharmaceuticals (Zuccato et al., 2009) and personal care products (Huerta-

Fontela et al., 2008a; Bartelt-Hunt et al., 2009). Among these contaminants of emerging concern, in

9 the last few years, the scientific literature shows an increasing interest in substances deriving from

illicit drug consumption (Richardson et al., 2014; Richardson, 2012). These compounds reach

1 wastewater treatment plants (WWTPs) through the drug users' urine and faeces and then are 
released into the environment unchanged or as metabolites (Zuccato et al., 2009; Castiglioni et al.,

53 2008). The eco-toxicological effects for most of these compounds are unknown, but their potential hazard cannot be excluded (Huerta-Fontela et al., 2008b; Kasprzyk-Hordern et al., 2008; Repice et al., 2008). Cannabinoids, cocaine, opiates, and amphetamine-like drugs are the most used illicit drugs worldwide (van Nuijs et al., 2011). Cocaine is the second most used illicit drug in Europe (World Drug Report, 2012). In the human body, only 1-9\% of consumed cocaine is excreted in urine as the unchanged parent drug, whereas the rest of it is metabolized to benzoylecgonine (45\%) and ecgonine methyl ester (40\%) (Castiglioni et al., 2008). Consequently, benzoylecgonine (Fig. 1) is the primary metabolite of cocaine, and it was found in almost all the WW and SurW samples in Europe and in other parts of the world at higher levels than its parent compound (Irvine et al., 2011; Yin Lai et al., 2013).

Moreover, while cocaine and its metabolite ecgonine methyl ester tend to spontaneously degrade in WW and SurW effluents (more or less rapidly depending on the $\mathrm{pH}$ and temperature), benzoylecgonine $(\mathrm{BE})$ concentration is almost constant or slightly increasing, due to its relative stability in aqueous matrices and the partial degradation of cocaine into BE (Castiglioni et al., 2006; Gheorghe et al., 2008; Castiglioni et al., 2011; van Nuijs et al., 2012). Tables S1 a-b in the supplementary information section show the BE levels reported in SurW and WWTPs effluents. The finding of BE in WWTPs effluents attests to the incomplete removal in conventional plants. Because of its relatively high levels in the inlet, even with good removal efficiency ( $\geq 80 \%)$, the levels in the effluents are still higher than other illicit drug contaminants (Huerta-Fontela et al., 2008; Kasprzyk-Hordern et al., 2008; Postigo et al., 2009; Repice et al., 2013; Du et al., 2014). Despite the presence of illicit drug contaminants in WW and SurW, there are only a few studies addressing the eco-toxicological effects of $\mathrm{BE}$ on the aquatic environment. The exposure of Dreissena polymorpha (a zebra mussel) to BE concentrations of 0.5 and $1.0 \mu \mathrm{g} \cdot \mathrm{L}^{-1}$, resulted in a 3.5 fold increase of the oxidative stress in comparison to the background level and either an increased or inhibited activity of antioxidant and detoxifying enzymes depending on the BE levels 
and the exposure time (Parolini et al., 2013). In addition, an increased peroxidation of lipids and protein carbonylation, DNA damage, and cellular apoptotic death were found in experiments carried out up to 14 days (Binelli et al., 2013). Even more detrimental damage cannot be excluded at longer exposure times and in concert with the effects of other WW and SurW micropollutants. The kinetic behaviour of $\mathrm{BE}$ during a disinfection stage for water reuse was previously investigated (Russo et al., 2016) treating contaminated milliQ water under $\mathrm{UV}_{254}$ radiation only.

The purpose of this study is to investigate the effect of an advanced oxidation process (AOP) with hydrogen peroxide and $\mathrm{UV}_{254}$ radiation on the removal and transformation of $\mathrm{BE}$ in four different aqueous matrices: milliQ water, synthetic wastewater (SWW), real wastewater (RWW) and SurW.

\subsection{Microcapillary photoreactor}

The degradation experiments were carried out in a novel microcapillary film (MCF) array photoreactor (Reis and Li Puma, 2015) consisting of 10 microcapillaries with a mean diameter of about $200 \mu \mathrm{m}$ transparent to UVC light. A schematic of the reactor is reported in fig. S1 in the supplementary information section. This experimental apparatus allows the use of very small volumes of reacting solution compared to the usual batch photo-reactors, leading to economic and environmental benefits. A significant benefit is the reduction of the volume of the experimental waste solution and decreased usage of costly border controlled substances, including the adoption of illicit drugs as the tested compounds. The cost of the low power ( $8 \mathrm{~W}) \mathrm{UV}$ lamp necessary for this kind of reactor is also very low. Moreover, as described elsewhere (Reis and Li Puma, 2015; Russo et al., 2016), the extremely small reactor volume and optical path length allows for complete conversion of the contaminant in a few seconds or a few minutes depending on the treatment adopted. This is possible as a result of the high surface/volume ratio achievable in a microcapillary reactor and high photon irradiance, which is realized even in optically thick fluids. Therefore, the MCF photoreactor represents a powerful tool for the rapid determination of photodegradation kinetics of contaminants in fluids at a laboratory scale. The wider impact of this study will be maximized by the integration of MCF with ultra-rapid analytics for the determination of 

minute quantities.

106

\subsection{Materials} products (TPs).

transformation products of contaminants of emerging concern which are often available only in

\section{Materials and methods}

Hydrogen peroxide $(30 \% \mathrm{v} / \mathrm{v})$, benzoylecgonine $(\geq 99 \% \mathrm{w} / \mathrm{w})$, acetonitrile $(\geq 99.9 \% \mathrm{v} / \mathrm{v})$, formic acid ( $\geq 95 \% \mathrm{v} / \mathrm{v})$, sodium hydroxide, and sulfuric acid were purchased from Sigma-Aldrich. The milli-Q water was prepared by a Millipore Elix water purification system.

Synthetic wastewater was prepared following the OECD Guidelines (Organisation for Economic Cooperation and Development, 1999) using milliQ water and peptone (32 ppm), meat extract (22 ppm), urea (6 ppm), $\mathrm{K}_{2} \mathrm{HPO}_{4}(28 \mathrm{ppm}), \mathrm{CaCl}_{2} \cdot \mathrm{H}_{2} \mathrm{O}$ (4 ppm), $\mathrm{NaCl}(7 \mathrm{ppm})$ and $\mathrm{Mg}_{2} \mathrm{SO}_{4}(0.6 \mathrm{ppm})$. These substances were purchased from Sigma-Aldrich. Real wastewater was sampled from the sewage water treatment plant of Festival Drive, Loughborough, Leichestershire (UK). Surface water was collected from the Grand Union Canal in the same zone. All the real water samples were filtered through Whatman nylon filters $(0.45 \mu \mathrm{m})$, to avoid clogging of the MCF and of the high performance liquid chromatography (HPLC) tubing. Furthermore, this allowed the direct evaluation of the degradation of $\mathrm{BE}$ in the different aqueous matrices without considering the effect of the suspended solid matter on the absorption of radiation and sorption of BE and its transformation

\subsection{Analytical methods}

The concentrations of hydrogen peroxide and BE in the samples were evaluated by HPLC analysis.

The HPLC (1100 Agilent) apparatus was equipped with a Gemini C18 (Phenomenex) reverse phase column and a diode array UV/VIS detector $(\lambda=232 \mathrm{~nm})$. The mobile phase consisted of a mixture of formic acid aqueous solution (25 mM) (A) and acetonitrile (B) flowing at $0.6 \mathrm{~mL} \mathrm{~min}^{-1}$. The following gradient was adopted: $7 \%$ B to $28 \% \mathrm{~B}$ in $9 \mathrm{~min}$, to $50 \% \mathrm{~B}$ in $5 \mathrm{~min}$, constant for $2 \mathrm{~min}$, and then to $35.7 \%$ in $3 \mathrm{~min}$, and finally returned to the initial conditions in $5 \mathrm{~min}$. The retention 
130 times of $\mathrm{H}_{2} \mathrm{O}_{2}$ and $\mathrm{BE}$ were $4.9 \mathrm{~min}$ and $13.8 \mathrm{~min}$, respectively. The $\mathrm{pH}$ of the reacting solutions

131 was measured with an Accumet Basic AB-10 pH-meter. A Perkin Elmer UV/VIS spectrometer

132 (Lambda 35) was used to determine the absorbance spectra of the aqueous matrices. The

133 conductivity and the total organic carbon (TOC) of the water samples were respectively measured

134 with a WPA Linton Cambridge CM35 conductivity meter and a TOC-5000A TOC analyzer

135 (Shimadzu). The nitrate and nitrite content were measured by means of ion chromatography

136 (Metrohm 761 Compact). Table 1 summarizes the main water features.

137 2.3. Experimental apparatus and procedures

138 2.3.1. Apparatus and treatment

139 The spiked solutions were prepared by adding the solid BE to each filtered aqueous matrix. The

140 initial concentration of BE in the solutions was kept in the range $2.8 \cdot 10^{-5} \pm 4.0 \cdot 10^{-6} \mathrm{~mol} \mathrm{~L}^{-1}$. This

141 value is much greater than the usual level of BE found in RWW and SurW (Tab. S1); however, it

142 was necessary to keep the concentration at a higher level for a better evaluation and comparison of

143 the removal kinetics and for the identification of the transformation byproducts.

144 In order to study the degradation of $\mathrm{BE}$ with the $\mathrm{UV}_{254} / \mathrm{H}_{2} \mathrm{O}_{2}$ process, a fluorinated ethylene-

145 propylene (FEP-Teflon) MCF photoreactor containing 10 capillaries with a mean hydraulic

146 diameter of $195 \mu \mathrm{m}$ was used. The description and the validation of the microreactor has been

147 described in detail elsewhere (Reis and Li Puma, 2015; Russo et al., 2016). As previously reported,

148 the microreactor was coiled around a $8 \mathrm{~W}$ (nominal power) UV monochromatic lamp (Germicidal

149 G8T5) emitting radiation at $254 \mathrm{~nm}$. The segments not coiled were covered with aluminum foil to

150 avoid UV radiation reaching these sections. Experiments were performed in continuous flow

151 through the reactor. The residence time (i.e., the reaction time) was changed by varying the length

152 of the reactor exposed to the $\mathrm{UV}_{254}$ radiation. Samples at different residence times were collected

153 from the outlet of the MCF after reaching the steady state condition (i.e., about 5 times the reactor

154 volume processed) and rapidly analyzed. The concentration of BE in the inlet to the reactor did not

155 vary during the experimental runs. All experiments were carried out at room temperature $\left(\sim 25^{\circ} \mathrm{C}\right)$. 
It was verified that thermostatic control was not necessary because at the outlet of the reactor, the temperature of the solution did not vary significantly. The $\mathrm{pH}$ of the reacting solutions was adjusted with dilute solutions of $\mathrm{NaOH}$ and $\mathrm{H}_{2} \mathrm{SO}_{4}$. At the end of each experiment, the $\mathrm{pH}$ of the solutions was re-measured and the results were always close to the initial value.

\subsubsection{Analysis of transformation products}

161 Aqueous reaction mixtures and untreated controls were extracted using solid phase extraction (SPE) 162 and analyzed using LC-mass spectrometry (MS)/MS. Water samples (150 mL) were passed through 163 SPE cartridges (Waters Oasis HLB, 6cc) at a rate of approximately $5 \mathrm{~mL} / \mathrm{min}$ and were eluted with $1648 \mathrm{~mL}$ of methanol, in $4 \mathrm{~mL}$ increments, using gravity elution. The eluted solutions were stored in 165 the freezer throughout the duration of the experiments. They were either used as is or blown down 166 using nitrogen to make a more concentrated solution.

167 Mass spectrometry analyses of TPs were carried out using a high resolution Thermo Orbitrap Velos 168 Pro (Thermo Scientific, Bremen, Germany). A nano-LC was coupled to the Orbitrap for 169 chromatographic separation. The flow rate was $0.300 \mu \mathrm{L} / \mathrm{min}$. Initial conditions were $2 \%$ organic 170 (acetonitrile) and were held for $5 \mathrm{~min}$. The percent organic was ramped linearly to $40 \%$ over the 171 next $10 \mathrm{~min}$, then ramped linearly to $95 \%$ over the next $40 \mathrm{~min}$, held at $95 \%$ for $10 \mathrm{~min}$, and then 172 returned to initial conditions. The capillary voltage was $1.8 \mathrm{kV}$. The column used was a picochip 173 C18 reversed phase column (10 cm x $75 \mu \mathrm{m} ; 3 \mu \mathrm{m}$; New Objective; Woburn, MA). The injection 174 volume was $1 \mu \mathrm{L}$ and the column temperature was held at room temperature. Full-scan and data175 dependent acquisition (DDA) MS/MS spectra were obtained using positive ion electrospray 176 ionization (ESI). The resolution was 30,000 for full-scan MS, and 7500 for DDA. The mass range 177 was $m / z$ 100-800.

178 A fraction containing two transformation product isomers (TP305) was also collected via 179 continuous fractionation with preparative LC-MS using a Waters 2000 series LC-mass spectrometer 180 with a C18 column and single quadrupole detector. An acetonitrile/water gradient was used, with a $181100 \mu \mathrm{L}$ injection volume and $1.0 \mathrm{~mL} / \mathrm{min}$ flow rate. The fractions were collected based on retention 
182

183

times. After collection, the sample was freeze dried and dissolved in deuterated methanol (d4) and analyzed using ${ }^{1} \mathrm{H}$ nuclear magnetic resonance (NMR) with a Bruker Avance III-HD $400 \mathrm{MHz}$ NMR spectrometer.

In this study, TPs are named using a number referring to their molecular mass (e.g., TP 305 refers to a TP with a molecular mass of $305 \mathrm{Da})$.

\section{Results and Discussion}

\subsection{Degradation Absorbance Characteristics}

Absorbance spectra were acquired to characterize and compare the different aqueous matrices. Fig. 2a. shows the characteristic absorption peak of BE in milliQ water at the wavelength of $232 \mathrm{~nm}$. No significant differences were observed in the spectra in the $\mathrm{pH}$ range 4-8. This was confirmed by the mean reported values of $\mathrm{pK}_{\mathrm{a} 1}$ and $\mathrm{pK}_{\mathrm{a} 2}$ of $\mathrm{BE}$, that are 3.35 and 10.45 , respectively (Jeanville et al., 2003; Marchi et al., 2009). The spectra of filtered SWW, RWW, and SurW are also displayed in Fig. 2b. The absorbances were nearly coincident for the real wastewater and surface water samples, whereas the synthetic wastewater showed very low absorbance at $254 \mathrm{~nm}$. This can be ascribed to the higher concentration of the aromatic compounds dissolved in the real wastewater and surface water samples compared to the lower concentrations of these in the synthetic wastewater, which is also supported by the TOC data in Table 1 . This difference does not significantly affect the BE removal, as further discussed, because of the different nature of the organic compounds.

Control experiments performed in $\mathrm{pH}$ range 4-8 with direct photolysis and with the $\mathrm{UV}_{254} / \mathrm{H}_{2} \mathrm{O}_{2}$ process showed insignificant differences in the removal of BE (data not shown).Consequently, all further experiments were run at $\mathrm{pH}=6.0$ in milliQ water and at natural $\mathrm{pH}$ for the other different aqueous matrices (Table 1). Moreover, no BE degradation was recorded in the presence of hydrogen peroxide $\left(\left[\mathrm{H}_{2} \mathrm{O}_{2}\right] /[\mathrm{BE}] \sim 500\right)$ without $\mathrm{UV}_{254}$ radiation (data not shown).

\subsection{Degradation Kinetics}


Figure 3 shows the removal percentage of $\mathrm{BE}$ by direct $\mathrm{UV}_{254}$ photolysis at different residence times in the MCF and with the different aqueous matrices that were examined, compared to previously published removal in milliQ water. Even though UV treatment is not often adequate for chemical removal, it is important to consider that in the case of water reuse, UV treatment is

211 indicated as a method to reduce the presence of pathogens. During this process a contemporary

212 transformation of chemicals cannot be excluded.

213 The removal rate of BE in the SWW sample was slower than in milliQ water. This rate difference 214 could be easily justified by the presence of several compounds in SWW that may act as inner filters 215 (optical competitors absorbing part of the radiation) since the absorption of the SWW at $254 \mathrm{~nm}$ 216 (Fig. 2) was slightly higher than the absorbance of milliQ represented by the zero line in the 217 absorbance spectrum. In spite of this, as reported elsewhere (De Laurentiis et al., 2012), while the 218 chromophoric dissolved organic matter would inhibit the direct photolysis of BE by an inner-filter 219 effect, it could simultaneously act as a producer of oxidant species that could promote BE degradation. Therefore, the degradation of BE showed in fig. 2 must be considered as a result of the balance of the effects described above.

Moreover, the BE removal percentage and rate in SurW is very close to the removal in milliQ water, whereas in RWW effluents is significantly faster. These phenomena occur despite both SurW and RWW samples having considerably greater absorbances than the milliQ water. This evidence could suggest that the inner filter effect from the dissolved species was fully or more than offset by the chemical nature of the organic compounds present in these water matrices. Specifically, the photolysis of nitrates are a supplementary source of hydroxyl radicals (Mack and Bolton, 1999) and 228 since the nitrate content of the RWW sample was double that of the SurW sample, (Table 2), the removal of BE in the RWW water matrix could be expected to be higher than in the SurW sample

230 (Fig. 3). This effect has also been reported for the removal of other water contaminants (Alif and 231 Boule, 1991; Pamela et al., 1998; Goldstein and Rabani, 2008; Keen et al., 2012; Ji et al., 2012; Li 
232 et al., 2014; Zaviska et al., 2014). The nitrate photolysis follows the pathways below (Mack and

233 Bolton, 1999):

$$
\begin{gathered}
\mathrm{NO}_{3}^{-} \stackrel{h v}{\rightarrow} \mathrm{NO}_{2}^{-}+\frac{1}{2} \mathrm{O}_{2} \\
\mathrm{NO}_{3}^{-} \stackrel{h v}{\rightarrow}\left[\mathrm{NO}_{3}^{-}\right]^{*} \\
{\left[\mathrm{NO}_{3}^{-}\right]^{*} \rightarrow \mathrm{NO}_{2}^{-}+\mathrm{O}\left({ }^{3} \mathrm{P}\right)} \\
{\left[\mathrm{NO}_{3}^{-}\right]^{*} \rightarrow \mathrm{NO}_{2}+\mathrm{O}^{\bullet-} \stackrel{\mathrm{H}_{2} \mathrm{O}}{\longrightarrow} \mathrm{NO}_{2}+\mathrm{HO}^{\bullet}+\mathrm{HO}^{-}}
\end{gathered}
$$

$234 \mathrm{HO}^{\bullet}$ radicals increase the removal rate of BE in the RWW sample by oxidizing the organic 235 contaminant (Fig. 3). The possibility that the photolysis of nitrite could contribute to the generation 236 of hydroxyl radicals is not considered because of their negligible content compared to nitrates 237 concentration (Tab. 1).

238 Once the effects of different aqueous matrices on the indirect photolysis of BE were investigated, 239 the removal of $\mathrm{BE}$ by $\mathrm{UV}_{254} / \mathrm{H}_{2} \mathrm{O}_{2}$ process was studied. The photolysis of the $\mathrm{H}_{2} \mathrm{O}_{2}$ molecule, with 240 radiation at $254 \mathrm{~nm}$, yields two strongly reactive $\mathrm{HO}^{\bullet}$ radicals. The reaction pathways can be 241 exemplified as follow:

$$
\begin{gathered}
\mathrm{H}_{2} \mathrm{O}_{2} \stackrel{h v}{\rightarrow} 2 \mathrm{HO}^{\bullet} \\
\mathrm{BE}+\mathrm{HO}^{\bullet} \rightarrow \text { Primary intermediates }
\end{gathered}
$$

Primary intermediates $+\mathrm{HO}^{\bullet} \rightarrow$ Secondary intermediates

$$
\begin{gathered}
\mathrm{HO}^{\bullet}+\mathrm{H}_{2} \mathrm{O}_{2} \rightarrow \mathrm{HO}_{2}^{\bullet}+\mathrm{H}_{2} \mathrm{O} \\
2 \mathrm{HO}_{2}^{\bullet} \rightarrow \mathrm{H}_{2} \mathrm{O}_{2}+\mathrm{O}_{2}
\end{gathered}
$$




$$
\text { Scavengers }+\mathrm{HO}^{\bullet} \rightarrow \mathrm{By}-\text { products }
$$

242 Reaction (10) describes the scavenging effect of the organic compounds naturally or artificially 243 present in the water. This reaction was not considered for the process in milliQ water due to the 244 absence of organic contaminants. However, $\mathrm{HO}^{\bullet}$ radical production via reactions 1-4 was 245 considered where necessary. Mack and Bolton (1999) report that, using UV and nitrate, hydroxyl 246 radical generation is not as efficient as the $\mathrm{HO}^{\bullet}$ production with hydrogen peroxide. The reduced $247 \mathrm{UV} /$ nitrate efficiency is due to the nitrate's low hydroxyl radical quantum yield in the $250 \mathrm{~nm}$ to $248350 \mathrm{~nm}$ range compared to the quantum yield of direct photolysis of hydrogen peroxide $\Phi_{254}^{\mathrm{H}_{2} \mathrm{O}_{2}}=$ $2490.5 \mathrm{~mol} \mathrm{ein}^{-1}$ (Nicole et al., 1990). Consequently reaction (5) is faster than (4) in the presence of 250 nitrates in the water.

251 Fig. 4 displays the effect of different $\left[\mathrm{H}_{2} \mathrm{O}_{2}\right]_{\mathrm{o}} /[\mathrm{BE}]_{\mathrm{o}}$ ratios on the removal efficiency in milliQ water, 252 where $\left[\mathrm{H}_{2} \mathrm{O}_{2}\right]_{\mathrm{o}}$ and $[\mathrm{BE}]_{\mathrm{o}}$ are respectively the initial concentrations of hydrogen peroxide and $\mathrm{BE}$. 253 Higher $\left[\mathrm{H}_{2} \mathrm{O}_{2}\right]_{0} /[\mathrm{BE}]_{\mathrm{o}}$ ratios resulted in greater percentages of removal. Fig. 5 shows the $\mathrm{BE}$ 254 percentage of removal at different $\left[\mathrm{H}_{2} \mathrm{O}_{2}\right]_{\mathrm{o}}[\mathrm{BE}]_{\mathrm{o}}$ ratios for the four types of water matrices at three 255 significant reaction times.

256 However, the gain in the removal percentage gradually lessens with increased $\left[\mathrm{H}_{2} \mathrm{O}_{2}\right]_{0} /[\mathrm{BE}]_{0}$ ratio, 257 such that the removal degree at a fixed reaction time reached a plateau for all aqueous matrices 258 investigated (Fig. 5). In effect, an increase of the relative hydrogen peroxide concentration results 259 also in increased rate of reaction (8) so that a smaller than expected amount of hydroxyl radicals is 260 effective in the degradation. The high $\left[\mathrm{H}_{2} \mathrm{O}_{2}\right]_{0} /[\mathrm{BE}]_{0}$ ratios adopted in this experiment can be 261 justified because in real wastewater samples collected worldwide, BE is just one of many 262 micropollutants found in effluents and in surface waters. A greater hydrogen peroxide concentration 263 may be necessary for efficient degradation of these different mixtures of xenobiotics normally 264 present in water bodies. 
265 A comparison of the time scale of $\mathrm{UV}_{254}$ direct photolysis against $\mathrm{UV}_{254} / \mathrm{H}_{2} \mathrm{O}_{2}$ removal of $\mathrm{BE}$

266 shows significantly different characteristic kinetics of the two processes. The $\mathrm{UV}_{254}$ radiation 267 treatment (Fig. 3) requires up to two orders of magnitude longer time for the degradation of BE 268 compared to the $\mathrm{UV}_{254} / \mathrm{H}_{2} \mathrm{O}_{2}$ process (Fig. 4). The difference in magnitude suggests that direct 269 photolysis is a negligible process during the AOPs and that it would be highly inefficient on its own 270 for BE degradation.

271 As shown in Fig. 5, BE removal is higher in milliQ water once all of the operating conditions are standardized between the different aqueous matrices. This phenomenon is due to the absence of organic molecules acting as scavengers of hydroxyl radicals. However, the presence of scavengers alone cannot justify the differences in rates between RWW effluent and natural SurW. The rate differences can be related to the balance between the contrasting effects of reactions 1-4. In almost all of the experiments, the removal percentages in RWW samples are slightly but significantly higher than in SurW. Similarly to what was reported for direct photolysis, this last evidence is in agreement with RWW having a higher nitrate concentration with respect to SurW since the absorbance of the two aqueous matrices is comparable (Fig 2).

\subsection{Transformation Products}

281 Several transformation products (TPs) resulting from UV photolysis and $\mathrm{UV} / \mathrm{H}_{2} \mathrm{O}_{2}$ treatment of BE were observed. These products increased in abundance with increasing reaction time, and they were tentatively identified using their accurate masses (Orbitrap-MS) and MS/MS fragmentation. Fig. 6 shows some of the most prominent TPs found in $\mathrm{UV} / \mathrm{H}_{2} \mathrm{O}_{2}$ reactions of $\mathrm{BE}$, in which $40 \%$ of $\mathrm{BE}$ was degraded ( $\sim 0.5 \mathrm{~s}$ reaction time). These products were also present at $90 \%$ and $100 \%$ degradation of BE, as well as in samples treated with UV only. Three of these TPs (TP 305a, 305b, and 305c, fig. 6a) appear to be isomers, each having an observed accurate mass of $m / z 306.1348$ (as the $(\mathrm{M}+\mathrm{H})^{+}$ion), and eluting at 20.56, 21.18, and 23.05 min, respectively. Their accurate mass suggests a molecular formula of $\mathrm{C}_{16} \mathrm{H}_{19} \mathrm{NO}_{5}$ (theoretical mass of $m / z$ of 306.1336). These TPs are likely monohydroxylated isomers, meta-, para-, and ortho- 
hydroxybenzoylecgonine. The MS/MS product ion spectra support these structural assignments. At a $\mathrm{CE}$ of $40 \mathrm{eV}$, two distinct fragments $(\mathrm{m} / \mathrm{z}, 168.1023$ and 121.0287 , fig. 7) matched viable fragmentation on the two bonds on either side of the ester oxygen (theoretical $\mathrm{m} / \mathrm{z}$ of 168.1024 and 121.0289, respectively, for these two fragment ions). In particular, the $m / z 121.0287$ fragment ion, with a formula of $\mathrm{C}_{7} \mathrm{H}_{5} \mathrm{O}_{2}$, indicates that hydroxyl radical addition occurs on the benzene ring, which is consistent with $\mathrm{UV}$ and $\mathrm{UV} / \mathrm{H}_{2} \mathrm{O}_{2}$ chemistry (Andreozzi et al., 2003).

Two of these TPs were isolated using preparative LC-MS, and NMR data supported the assignment of the ortho- and para-hydroxylated TPs. Despite low levels collected from these reaction mixtures, there was strong evidence for the ortho-hydroxy-BE [H6 d $(\mathrm{J}=5.5 \mathrm{~Hz}), \delta=8.208$ ppm; $\mathrm{H} 4 \mathrm{~m}, \delta=$ 7.740 ppm; H3 d $(\mathrm{J}=8.04 \mathrm{~Hz}), \delta=7.630$ ppm; H5 t $(\mathrm{J}=8.04 \mathrm{~Hz}), \delta=7.478$ ppm]. The parahydroxy-BE assignment was also suggested by NMR data $[\mathrm{H} 2,6$ broad singlet, $\delta=7.831 \mathrm{ppm} ; \mathrm{H} 3,5$ broad singlet $\delta=7.207 \mathrm{ppm}]$, but it was not as definitive, due to lower levels of this TP isolated relative to the ortho isomer. These TPs were also reported as by-products formed during two solar photocatalytic treatments $\left(\mathrm{TiO}_{2}\right.$ photocatalysis and photo-Fenton) of cocaine in water (Postigo et al. 2011).

TP 321 was observed at $m / z 322.1300\left((\mathrm{M}+\mathrm{H})^{+}\right.$ion $)$. This TP is likely dihydroxybenzoylecgonine, which has a theoretical $\mathrm{m} / z$ of 322.1285 for the $(\mathrm{M}+\mathrm{H})^{+}$ion. This TP eluted at 19.36, 21.84 min, and 25.12 min, and likely has both hydroxyl substituents on the benzene ring, consistent with TP 305a, 305b, and 305c, and consistent with hydroxyl radical chemistry. It is currently not known which

311 chromatographic peaks in Fig. 6B indicate three isomers of dihydroxybenzoylecgonine, all of which 312 have the two hydroxyl substituents on the aromatic ring. When the TP was fragmented using CID $313(27 \mathrm{eV})$, the resulting fragmentation pattern matches the half of the parent molecule with the 314 bridged ring and no evidence of the hydroxyl groups. The half with the aromatic ring (and hydroxyl 315 groups) breaks off as a neutral molecule and is not observed by the detector. Three chromatographic 316 peaks for TP 321 were seen in the MS/MS data, and all of them yielded the same fragmentation 
317 pattern as discussed above. Work continues to identify other less predominant TPs, as well as to

318 collect additional individual TP fractions (using preparative-LC-MS) for nuclear magnetic

319 resonance (NMR) analysis and confirmation of proposed chemical structures. NMR is particularly

320 helpful for determining substituent positions, and can aid in the identification of specific isomers for

321 TPs for cases where MS spectra are not definitive (Wendel et al., 2014; Luft et al., 2014). Further

322 chemical characterization of transformation products will be done using 2-dimensional NMR

323 spectroscopy on transformation products isolated with preparative-LC, and further mass

324 spectrometry analyses will be performed using targeted MS/MS on selected degradation products.

\section{Conclusions}

328 - The microfluidics approach adopted in this study allowed a full investigation on the removal of 329 benzoylecgonine by photolysis and the $\mathrm{UV}_{254} / \mathrm{H}_{2} \mathrm{O}_{2}$ process using minute quantities (100 $\mathrm{mg}$ ) of 330 this border controlled substance.

331 - Benzoylecgonine, the primary human urinary metabolite of cocaine, was efficiently removed by $332 \mathrm{UV}_{254}$ photolysis coupled with $\mathrm{H}_{2} \mathrm{O}_{2}$ in a microcapillary film photoreactor at approximately neutral $333 \mathrm{pH}$. The removal efficiency was affected by the nature of the aqueous matrix.

334 - Mass spectrometry analyses showed a significant decrease of benzoylecgonine and subsequent 335 increase in transformation products. The potential toxicity of these compounds is as yet unknown.

337 Acknowledgements

338 The Authors are grateful to ERASMUS-Mobility Student Program, and also to Hannah Liberatore 339 and Perry Pellechia from USC for assistance with NMR analysis of transformation products.

\section{$341 \quad$ References}


Alif, A., Boule, P., 1991. Photochemistry and environment part XIV. Phototransformation of

343 nitrophenols induced by excitation of nitrite and nitrate ions. J. Photochem. Photobiol. A: Chem.

$34459,357-367$.

345 Andreozzi, R., Caprio, V., Marotta, R., Vogna, D., 2003. Paracetamol oxidation from aqueous

346 solutions by means of ozonation and $\mathrm{H}_{2} \mathrm{O}_{2} / \mathrm{UV}$ system. Water Research 37, 993-1004.

347 Asu, Z., Nilsun, H.I., 2011. The occurrence and fate of anti-inflammatory and analgesic

348 pharmaceuticals in sewage and fresh water: Treatability by conventional and non-conventional 349 processes. Journal of Hazardous Materials 187, 24-36.

350 Bartelt-Hunt, S.L., Snow, D.D., Damon, T., Shockley, J., Hoagland, K., 2009. The occurrence of 351 illicit and therapeutic pharmaceuticals in wastewater effluent and surface waters in Nebraska.

352 Environmental Pollution 157, 786-791.

353 Berset, J.D., Brenneisen, R., Mathieu, C., 2010. Analysis of licit and illicit drugs in waste, surface 354 and lake water samples using large volume direct injection high performance liquid

355 chromatography - electrospray tandem mass spectrometry (HPLC-MS/MS). Chemosphere 81, 859356866.

357 Bijlsma, L., Emke, E., Hernandez, F., de Voogt, P., 2012. Investigation of drugs of abuse and 358 relevant metabolites in Dutch sewage water by liquid chromatography couples to high resolution 359 mass spectrometry. Chemosphere 89, 1399-1406.

360 Binelli, A., Marisa, I., Fedorova, M., Hoffmann, R., Riva, C., 2013. First evidence of protein profile 361 alteration due to main cocaine metabolite (benzoylecgonine) in a freshwater biological model. 362 Aquatic Toxicology 140-141, 268-278.

363 Bones, J., Thomas, K.V., Brett, P., 2007. Using environmental analytical data to estimate levels of 364 community consumption of illicit drugs and abused pharmaceuticals. Journal of Environmental 365 Monitoring 9, 701-707. 
366 Castiglioni, S., Zuccato, E., Crisci, E., Chiarabrando, C., Fanelli, R., Bagnati, R., 2006.

367 Identification and measurements of illicit drugs and their metabolites in urban wastewater by liquid 368 chromatography-tandem mass spectrometry. Analytical Chemistry 78(24), 8421-8429.

369 Castiglioni, S., Zuccato, E., Chiarabrando, C., Fanelli, R., Bagnati, R., 2008. Mass spectrometric 370 analysis of illicit drugs in wastewater and surface water. Mass Spectrometry Reviews 27, 378-394.

371 Castiglioni, S., Bagnati, R., Melis, M., Panawennage, D., Chiarelli, P., Fanelli, R., Zuccato, E., 372 2011. Identification of cocaine and its metabolites in urban wastewater and comparison with human 373 excretion profile in urine. Water Research 45, 5141-5150.

374 Corominas, L., Foley, J., Guest, J.S., Hospido, A., Larsen, H.F., Morera, S., Shaw, A., 2013. Life 375 cycle assessment applied to wastewater treatment: State of the art. Water Research 47, 5480-5492. 376 De Laurentiis, E., Chiron, S., Kouras-Hadef, S., Richard, C., Minella, M., Maurino, V., Minero, C., 377 Vione, D., 2012. Photochemical fate of carbamazepine in surface freshwaters: laboratory measures 378 and modelling. Environmental Science \& Technology 46, 8164-8173.

379 Du, B., Price, A.E., Scott, W.C., Kristofco, L.A., Ramirez, A.J., Chambliss, C.K., Yelderman, J.C., 380 Brooks, B.W., 2014. Comparison of contaminants of emerging concern removal, discharge, and 381 water quality hazards among centralized and on-site wastewater treatment system effluents 382 receiving common wastewater influent. Science of Total Environment 466-467, 976-984.

383 Gheorghe, A., Van Nuijs, A., Pecceu, B., Bervoets, L., Jorens, P.G., Blust, R., Neels, H., Covaci, 384 A., 2008. Analysis of cocaine and its principal metabolites in waste and surface water using solid385 phase extraction and liquid chromatography-ion trap tandem mass spectrometry. Anal. Bioanal. 386 Chem. 391, 1309-1319.

387 Goldstein, A., Rabani, J., 2008. Polychromatic UV photon irradiance measurements using chemical 388 actinometers based on $\mathrm{NO}_{3}{ }^{-}$and $\mathrm{H}_{2} \mathrm{O}_{2}$ excitation: applications for industrial photoreactors

389 Environmental Science \& Technology 42, 3248-3253. 
Huerta-Fontela, M., Galceran, M.T., Ventura, F., 2007. Ultraperformance liquid chromatograph-

391 tandem mass spectrometry analysis of stimulatory drugs of abuse in wastewater and surface waters. 392 Analytical Chemistry 79, 3821-3829.

393 Huerta-fontela, M., Galceran, M.T., Ventura, F., 2008a. Stimulatory drugs of abuse in surface 394 waters and their removal in a conventional drinking water treatment plant. Environmental Science $395 \&$ Technology 42, 18.

396 Huerta-Fontela, M., Galceran, M.T., Martin-Alonso, J., Ventura, F., 2008b. Occurrence of 397 psychoactive stimulatory drugs in wastewaters in noth-eastern Spain. Science of the Total 398 Environment 397, 31-40.

399 Hummel, D., Loeffler, D., Fink, G., Ternes, T.A., 2006. Simultaneous determination of 400 psychoactive drugs and their metabolites in aqueous matrices by liquid chromatography mass 401 spectrometry. Environmental Science and Technology 40, 7321-7328.

402 Irvine, R.J., Kostakis, C., Felgate, P.D., Jaehne, E.J., Chen, C., White, J.M., 2011. Population drug 403 use in Australia: a wastewater analysis. Forensic Science International 210, 69-73.

404 Jeanville, P. M., Estapé, E.S., Torres-Negròn de Jeanville, I., 2003. The effect of liquid 405 chromatography eluents and additives on the positive ion responses of cocaine, benzoylecgonine, 406 and ecgonine methyl ester using electrospray ionization. International Journal of Mass Spectrometry $407 \quad 227,247-258$.

408 Ji, Y., Zeng, C., Ferronato, C., Chovelon, J., Yang, X., 2012. Nitrate-induced photodegradation of 409 atenolol in aqueous solution: kinetics, toxicity and degradation pathways. Chemosphere 88, 644410649.

411 Karolak, S., Nefau, T., Bailly, E., Solgadi, A., Levi, Y., 2010. Estimation of illicit drugs 412 consumption by wastewater analysis in Paris area (France). Forensic Science International 200, $413 \quad 153-160$. 
414 Kasprzyk-Hordern, B., Dinsdale, R.M., Guwy, A.J., 2008. The occurrence of pharmaceuticals, 415 personal care products, endocrine disruptor and illicit drugs in surface water in South Wales, UK. 416 Water Research 42, 3498-3518.

417 Kasprzyk-Hordern, B., Dinsdale, R.M., Guwy, A.J., 2009. The removal of pharmaceuticals, 418 personal care products, endocrine disruptors and illicit drugs during wastewater treatment and its 419 impact on the quality of receiving waters. Water Research 43, 363-380.

420 Keen, O.S., Love, N.G., Linden, K.G., 2012. The role of effluent nitrate in trace organic chemical 421 oxidation during UV disinfection. Water Research 46, 5224-5234. enrofloxacin photolysis in an aqueous system under three light conditions: kinetics and mechanism. 424 Environmental Chemistry 11(3), 333-340.

425 Luft, A., Wagner, M., Ternes, T.A., 2014. Transformation of Biocides Irgarol and Terbutryn in the 426 Biological Wastewater Treatment. Environmental Science \& Technology 48, 244-254.

427 Mack, J., Bolton, J.R., 1999. Photochemistry of nitrite and nitrate in aqueous solution: a review. 428 Journal of Photochemistry and Photobiology A 128, 1-13.

429 Marchi, I., Rudaz, S., Veuthey, J., 2009. Sample preparation development and matrix effects 430 evaluation for multianalyte determination in urine. Journal of Pharmaceutical and Biomedical 431 Analysis 49, 459-467.

432 Mari, F., Politi, L., Biggeri, A., Accetta, G., Trignano, C., Di Pauda, M., Bertol, E., 2009. Cocaine 433 and heroin in waste water plants: a 1-year study in the city of Florence, Italy. Forensic Science 434 International 189, 88-92.

435 Mendoza, A., Lopez de Alda, M., Gonzalez-Alonso, S., Mastroianni, N., Barcelò, D., Valcarcel, Y., 436 2014. Occurrence of drugs of abuse and benzodiazepines in river waters from the Madrid Region 437 (Central Spain). Chemosphere 95, 247-255. 

municipal wastewater and estimates of community drug use. Environmental Pollution 158, 3179-

4403185.

441 Nicole, I., De Laat, J., Doré, M., Duguet, J.P., Bonnel, C., 1990. Use of UV radiation in water 442 treatment: measurement of photonic flux by hydrogen peroxide actinometry. Water Research 24, $443 \quad 157-168$.

444 Organisation for Economic Cooperation and development (OECD), 1999. Guidelines for testing of 445 Chemicals, Simulation Test-Aerobic Sewage Treatment. 303A.

446 Pamela, P., Vaughan and Neil V. Blough, 1998. Photochemical formation of hydroxyl radical by 447 constituents of natural waters. Environmental Science \& Technology 32, 2947-2953.

448 Parolini, M., Pedriali, A., Riva, C., Binelli, A., 2013. Sub-lethal effects caused by the cocaine 449 metabolite benzoylecgonine to the freshwater mussel Dreissena polymorpha. Science of Total 450 Environment 444, 43-50.

451 Pedrouzo, M., Borrull, F., Pocurull, E., Marcè, R.M., 2011. Drugs of abuse and their metabolites in 452 waste and surface waters by liquid chromatography-tandem mass spectrometry. Journal of 453 Separation Science 34, 1091-1101.

454 Postigo, C., Lopez de Alda, M.J., Barcelo, D., 2008. Fully automated determination in the low 455 nanogram per litre level of different classes of drugs of abuse in sewage water by on-line solid456 phase extraction-liquid chromatography-electrospray-tandem mass spectrometry. Analytical 457 Chemistry 80, 3123-3134.

458 Postigo, C., Lopez de Alma, M.J., Barcelo, D., 2010. Drugs of abuse and their metabolites in the 459 Ebro River basin: occurrence in sewage and surface water, sewage treatment plants removal 460 efficiency, and collective drug usage estimation. Environment International 36, 75-84.

461 Reis, N.M., Li Puma, G., 2015. Novel microfluidics approach for extremely fast and efficient 462 photochemical transformations in fluoropolymer microcapillary films, Chem. Commun. 51 (40), $463 \quad 8414-8417$. 
464 Postigo, C., Sirtori, C., Oller, I., Malato, X., Ignacio Maldonado, M., Lopez de Alda, M., Barcelo, 465 D., 2011. Solar transformation and photocatalytic treatment of cocaine in water: kinetics, 466 characterization of major intermediate products and toxicity evaluation. Applied Catalysis B: 467 Environmental 104, 37-48.

468 Repice, C., Dal Grande, M., Maggi, R., Pedrazzani, R., 2013. Licit and illicit drugs in a wastewater 469 treatment plant in Verona, Italy. Science of the Total Environment 463-464, 27-34.

470 Richardson, S.D., Ternes, T.A., 2014. Water analysis: Emerging contaminants and current issues. 471 Analytical Chemistry 86, 2813-2848.

472 Richardson, S.D., 2012. Environmental Mass Spectrometry: Emerging Contaminants and current 473 issues. Analytical Chemistry 84, 747-778.

474 Russo, D., Spasiano, D., Vaccaro, M., Andreozzi, R., Li Puma, G., Reis, N.M., Marotta, R., 2016. 475 Direct photolysis of benzoylecgonine under UV irradiation at $254 \mathrm{~nm}$ in a continuous flow 476 microcapillary film (MCF) array photoreactor. Chemical Engineering Journal 283, 243-250. 477 Terzic, S., Senta, I., Ahel, M., 2010. Illicit drugs in wastewater of the city of Zagreb (Croatia) 478 estimation of drug abuse in a transition country. Environmental Pollution 158, 2686-2693. 479 Valcarcel, Y., Martinez, F., Gonzalez-Alonso, S., Segura, Y., Català, M., Molina, R., Montero480 Rubio, J.C., Mastroianni, N., Lopez de Alma, M., Postigo, C., Barcelò, D., 2012. Drugs of abuse in 481 surface and tap waters of the Tagus River basin: heterogeneous photo-Fenton is effective in their 482 degradation. Environment International 41, 35-43.

483 Van Nuijs, A.L.N., Pecceu, B., Theunis, L., Dubois, N., Charlier, C., Jorens, P.G., Bervoets, L., 484 Blust, R., Neels, H., Covaci, A., 2009. Cocaine and metabolites in waste and surface water across 485 Belgium. Environmental Pollution 157, 123-129.

486 Van Nuijs, A.L.N., Castiglioni, S., Tarcomnicu, I., Postigo, C., Lopez de Alda, M., Neels, H., 487 Zuccato, E., Barcelo, D., Covaci, A., 2011. Illicit drug consumption estimations derived from 488 wastewater analysis: a critical review. Science of the Total Environment 409, 3564-3577. 
Van Nuijs, A.L.N., Abdellati, K., Bervoets, L., Blust, R., Jorens, P.G., Neels, H., Covaci, A., 2012.

490 The stability of illicit drugs and metabolites in wastewater, an important issue for sewage

491 epidemiology? Journal of Hazardous Materials 239-240, 19-23.

492 Vazquez-Roig, P., Andreu, V., Blasco, C., Pico, Y., 2010. SPE and LC-MS/MS determination of 14 493 illicit drugs in surface waters from the Natural Park of L'Albufera (Valencia, Spain). Analytical and 494 Bioanalytical Chemistry 397, 2851-2864.

495 Wendel, F.M., Luetke Eversloh, C., Machek, E.J., Duirk, S.E., Plewa, M.J., Richardson, S.D., 496 Ternes, T.A., 2014. Transformation of iopamidol during chlorination. Environmental Science \& 497 Technology 48, 12689-12697.

498 World Drug Report, 2012. United Nations Office on Drugs and Crime. Vienna 1-112.

499 Yin Lai, F., Bruno, R., Leung, H.W., Thai, P.K., Ort, C., Carter, S., Thompson, K., Lam, P.K.S., 500 Mueller, J.F., 2013. Estimating daily and diurnal variations of illicit drug use in Hong Kong: a pilot 501 study of using wastewater analysis in an Asian metropolitan city. Forensic Science International $502 \quad 233,126-132$.

503 Zaviska, F., Droqui, P., El Hachemi, E.M., Naffrechoux, E., 2014. Effect of nitrate ions on the 504 efficiency of sonophotochemical phenol degradation. Ultrasonics Sonochemistry 21, 69-75. 505 Zuccato, E., Chiarabrando, C., Castiglioni, S., Calamari, D., Bagnati, R., Schiarea, S., Fanelli, R., 506 2005. Cocaine in surface water: a new evidence-based tool to monitor community drug abuse.

507 Environmental Health 4, 14.

508 Zuccato, E., Castiglioni, S., Bagnati, R., Chiarabrando, C., Grassi, P., Fanelli, R., 2008. Illicit drugs, 509 a novel group of environmental contaminants. Water Research 42, 961-968.

510 Zuccato, E., Castiglioni, S., 2009. Illicit drugs in the environment. Philosophical Transactions of the $511 \quad$ Royal Society A 367. 


\begin{tabular}{|c|c|c|c|c|c|}
\hline Water & $\mathbf{p H}$ & $\begin{array}{c}\text { Conductivity } \\
(\boldsymbol{\mu S})\end{array}$ & TOC (ppm) & Nitrates & Nitrites \\
matrix & & 2.5 & 0.248 & 1.0 & $\mathbf{0}$ \\
\hline MilliQ & 6.0 & 80 & 20.79 & 1.0 & $\mathbf{0}$ \\
\hline SWW & 6.0 & 960 & 43.25 & 52.4 & $\mathbf{0 , 1 7}$ \\
\hline RWW & 7.6 & 930 & 46.37 & 25.8 & $\mathbf{0 , 0 4}$ \\
\hline SurW & 7.8 & & & & \\
\hline
\end{tabular}

Tab. 1. Measured parameters of different aqueous matrices. MilliQ (milliQ water); SWW (synthetic wastewater); RWW (real wastewater); SurW (surface water). 


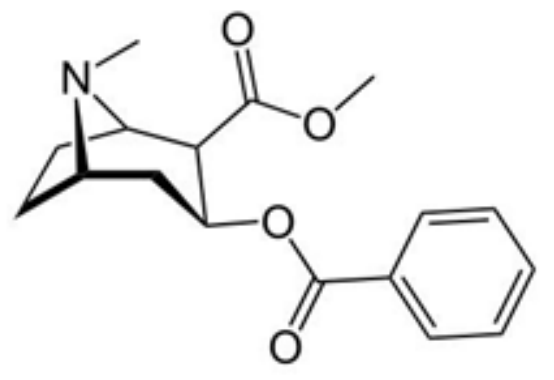

Cocaine

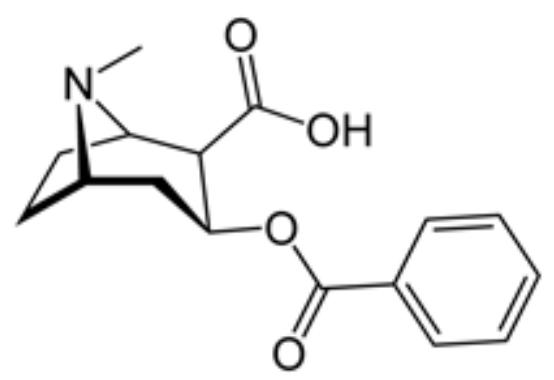

Benzoylecgonine

Fig. 1. Molecular structures of cocaine and benzoylecgonine.

black and white in print is required. 


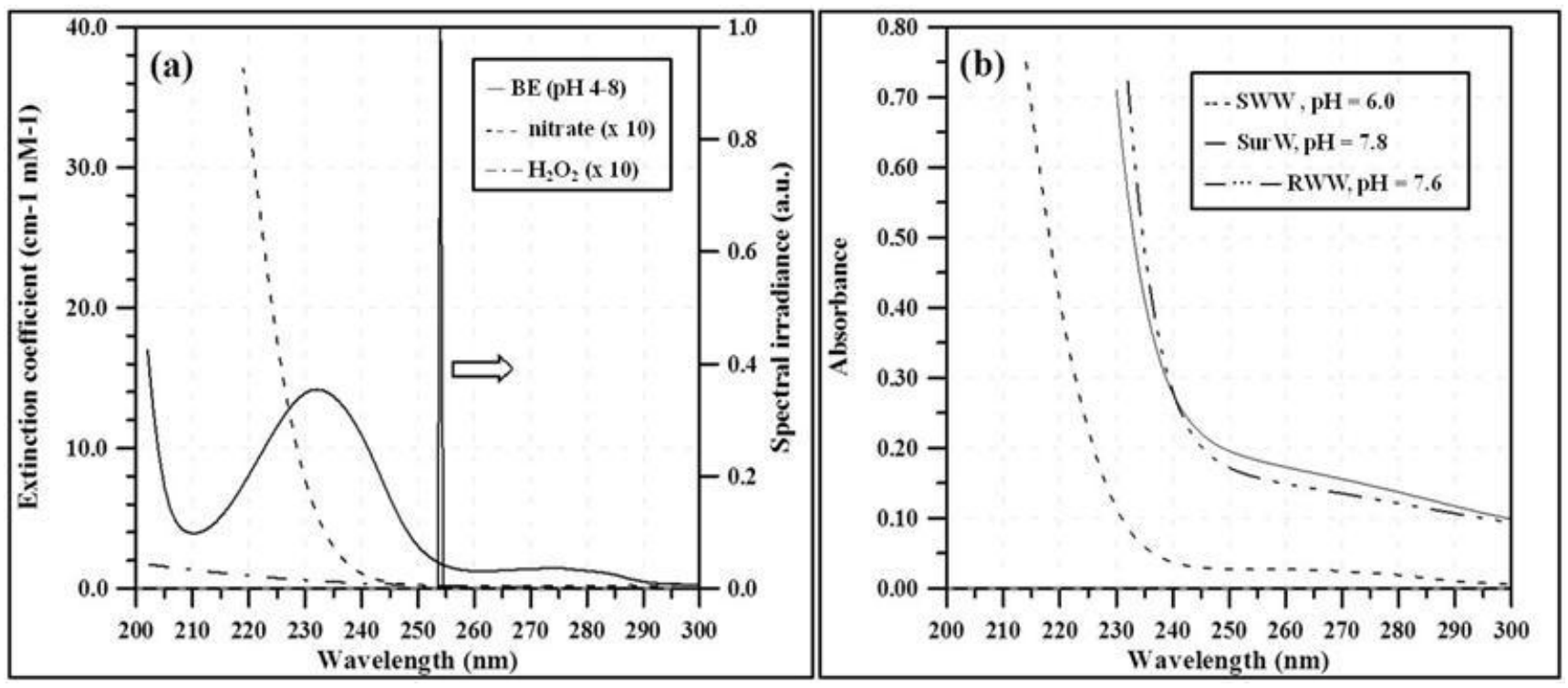

Fig. 2.

Fig. 2a. Extinction coefficient of BE, nitrate and hydrogen peroxide in milliQ water and spectra irradiance of the $\mathbf{U V}_{254}$ lamp.

Fig. 2b. Absorbance of the different aqueous matrices.

Black and white in print is required 


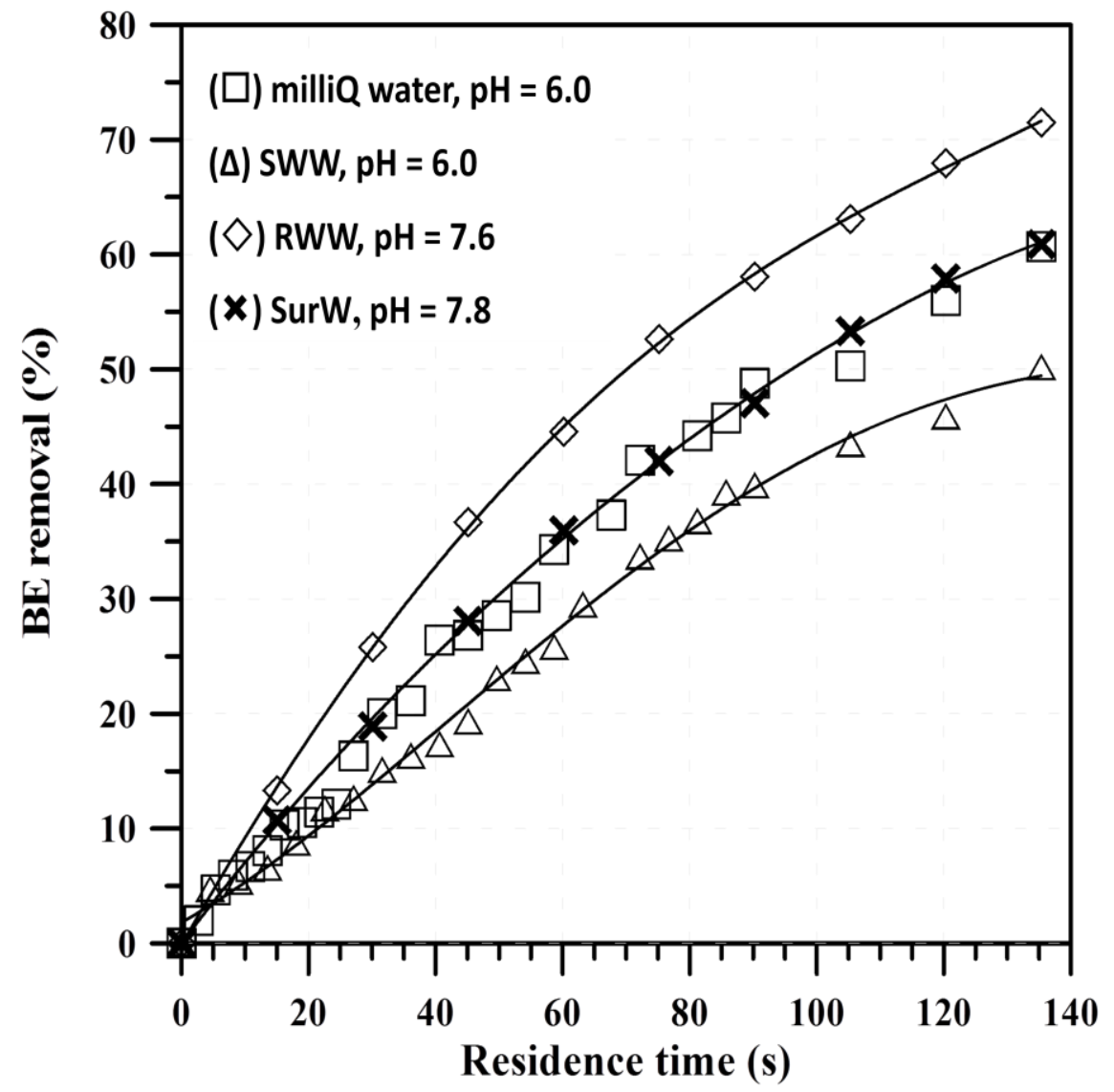

Fig. 3. Removal degree of BE through direct photolysis process. Effect of aqueous matrix. SWW (Synthetic Waste Water) - RWW (Real Waste Water) - SurW (Surface Water). (MilliQ Water, pH = 6.0, data from Russo et al., 2015).

Black and white in print is required. 


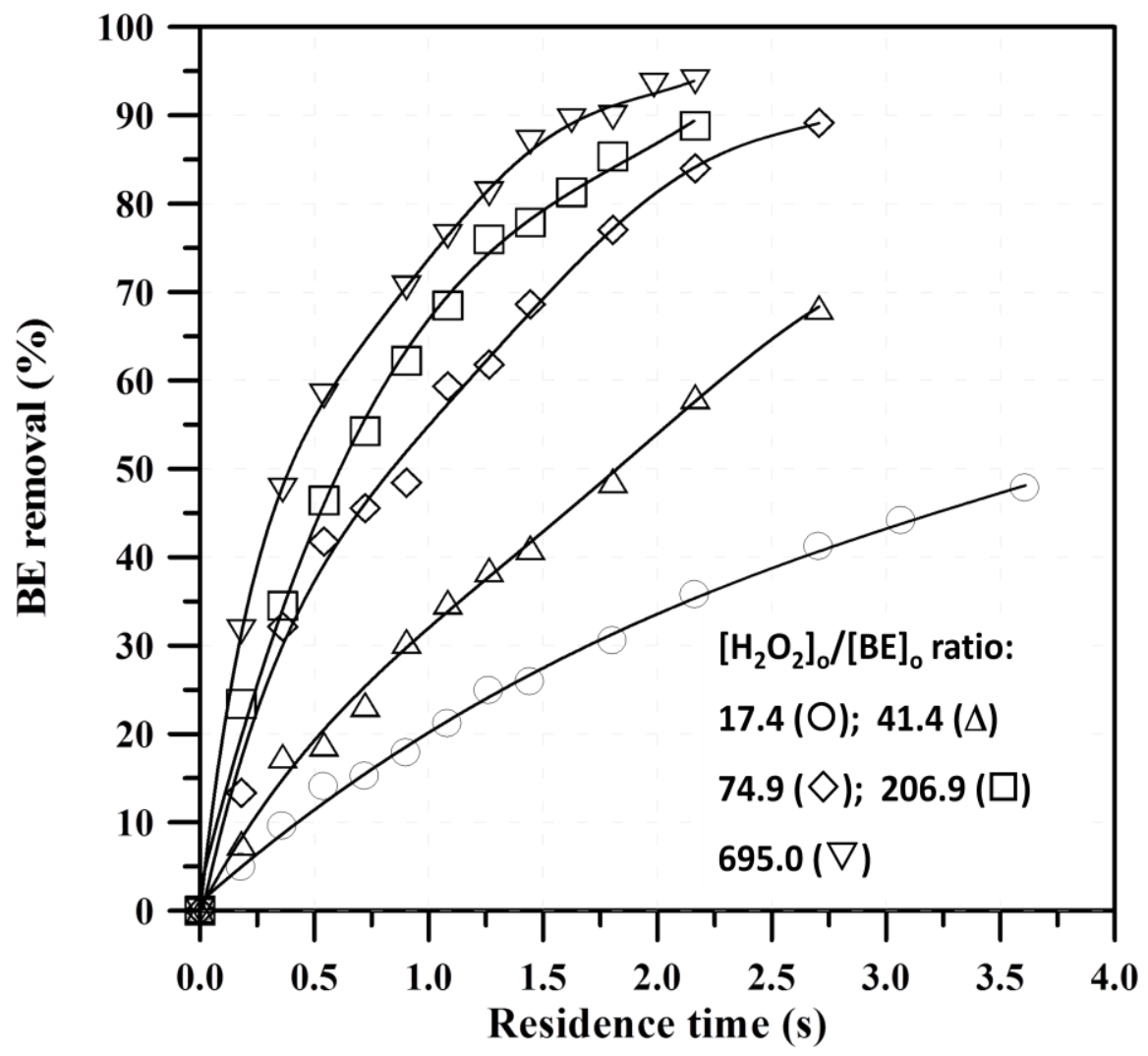

Fig. 4. Removal degree of $\mathrm{BE}$ through $\mathrm{UV}{ }_{254} / \mathrm{H}_{2} \mathrm{O}_{2}$ process in milliQ water: effect of $\left[\mathrm{H}_{2} \mathrm{O}_{2}\right]_{0} /[\mathrm{BE}]_{0}$ ratio at $\mathrm{pH}=6.0$.

Black and white in print is required. 


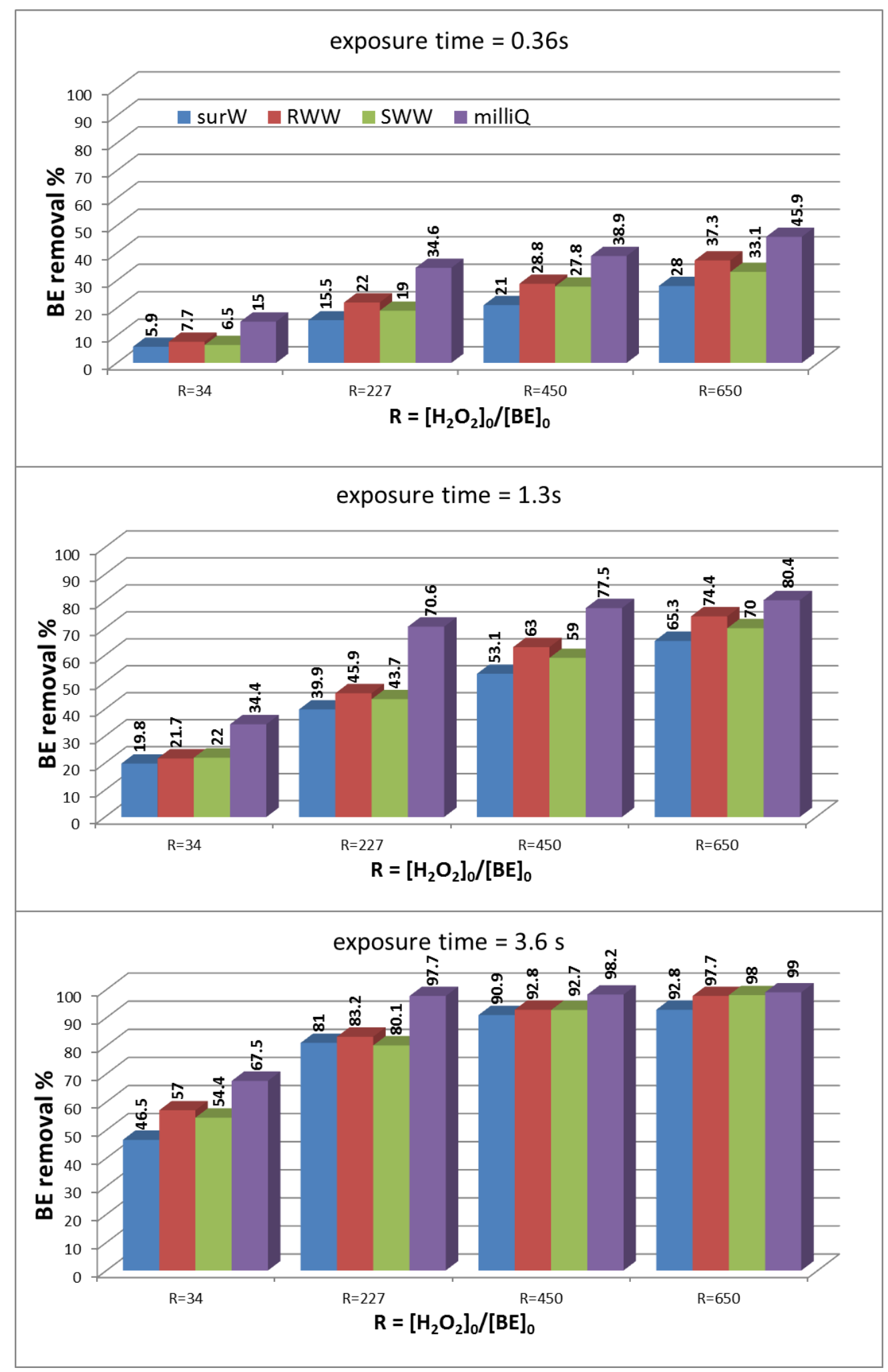

Fig. 5. BE removal degree in different aqueous matrices at various $\left[\mathrm{H}_{2} \mathrm{O}_{2}\right]_{0} /[\mathrm{BE}]_{0}$ ratios and contact time during $\mathrm{UV} / \mathrm{H}_{2} \mathrm{O}_{2}$ treatment.

Color in print is required. 

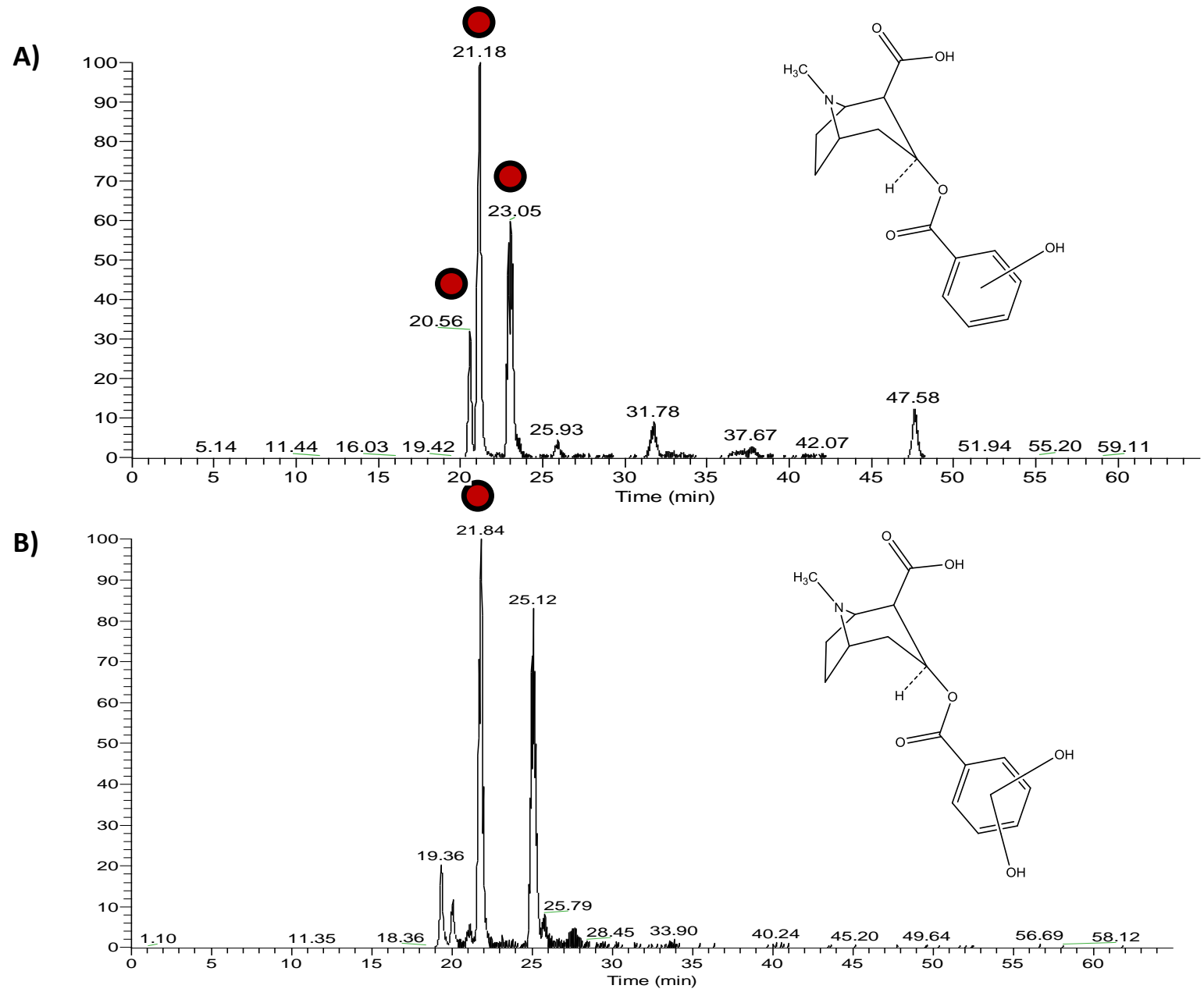

Fig. 6. Extracted ion LC-MS chromatograms for: A) TP 305a, TP 305b, and TP 305c; and B) TP 321, resulting from $\mathrm{UV} / \mathrm{H}_{2} \mathrm{O}_{2}$ reactions with $\mathrm{BE}(\sim 0.5 \mathrm{~s}$ reaction time, $40 \%$ degradation of $\mathrm{BE})$. 


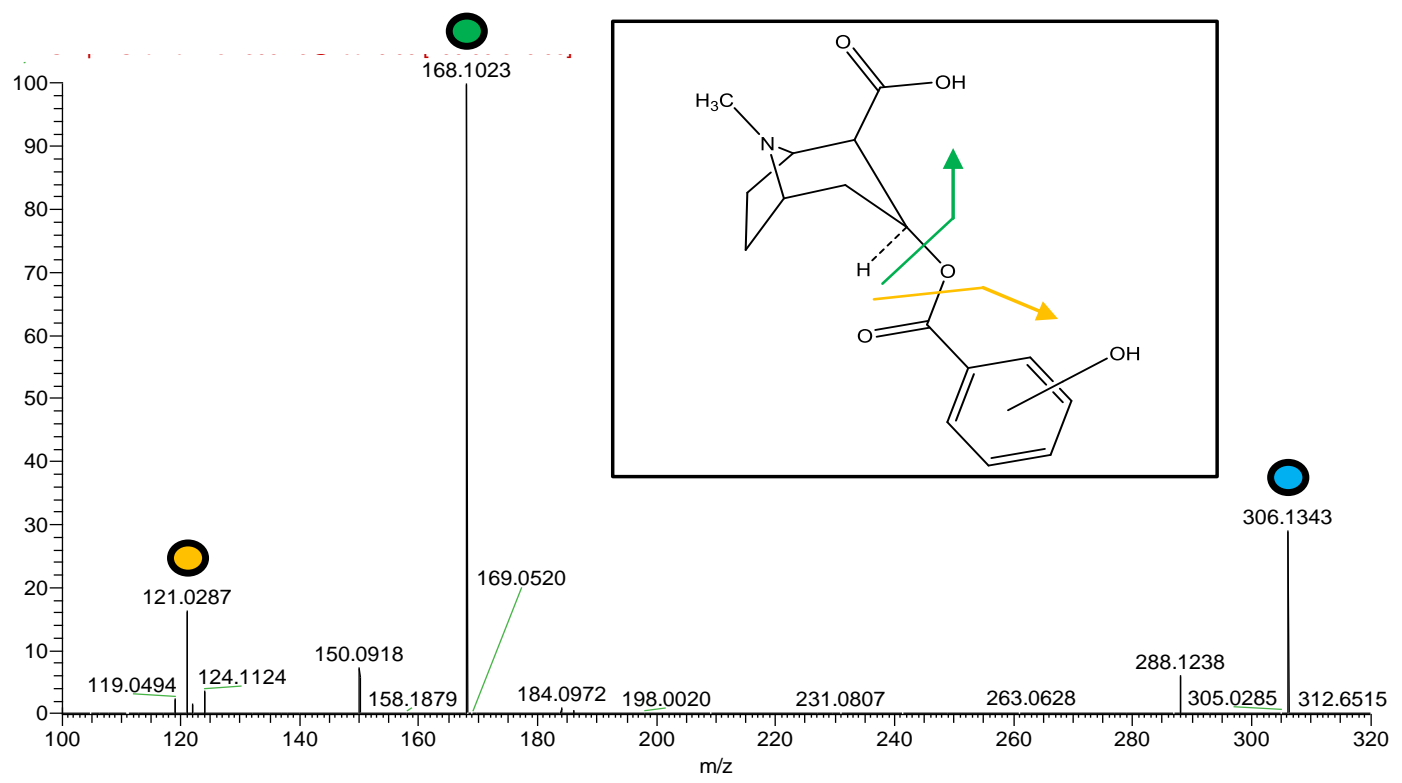

Fig. 7. Product ion MS/MS spectrum of $m / z, 306.1343\left((M+H)^{+}\right.$ion of TP 305) with proposed fragmentation sites.

Color in print is required. 
Click here to download Electronic Supplementary Material (for online publication only): supplementary data.docx Supplementary data (figure and tables)
Click here to download Electronic Suppl 